\title{
The Effect of Cardiac Rehabilitation Exercise Training on Cardiopulmonary Function in Ischemic Cardiomyopathy With Reduced Left Ventricular Ejection Fraction
}

\author{
Chul Kim, MD ${ }^{1}$, Hee Eun Choi, $\mathrm{MD}^{2}$, Young-Joon Lim, MD \\ ${ }^{1}$ Department of Rehabilitation Medicine, Inje University Sanggye Paik Hospital, Inje University College of Medicine, Seoul; \\ ${ }^{2}$ Department of Rehabilitation Medicine, Inje University Haeundae Paik Hospital, Inje University College of Medicine, Busan, Korea
}

\begin{abstract}
Objective To observe the effect and safety of cardiac rehabilitation (CR) exercise in ischemic cardiomyopathy and to compare the results between patients with preserved left ventricular ejection fraction (LVEF) and reduced LVEF. Methods Patients with ischemic cardiomyopathy with LVEF $<50 \%$ were included as subjects. The patients were classified into the preserved LVEF (pLVEF; LVEF 41\%-49\%) group and the reduced LVEF (rLVEF; LVEF $\leq 40 \%$ ) group. Patients underwent hourly aerobic exercise training sessions with an intensity of $60 \%-85 \%$ of heart rate reserve, three times a week for 6 weeks. Graded exercise test and transthoracic echocardiogram were performed in all study patients before and after completion of the CR exercise program.

Results After completion of the CR exercise program, both groups (pLVEF, $n=30$; rLVEF, $n=18$ ) showed significant increases in LVEF and $\mathrm{VO}_{2 \max }$. In the pLVEF group, LVEF and $\mathrm{VO}_{2 \max }$ increased from $45.1 \% \pm 4.8 \%$ to $52.5 \% \pm 9.6 \%$ ( $\mathrm{p}<0.001$ ) and from $24.1 \pm 6.3$ to $28.1 \pm 8.8 \mathrm{~mL} / \mathrm{kg} / \mathrm{min}$ ( $\mathrm{p}=0.002$ ), respectively. In the rLVEF group, LVEF and $\mathrm{VO}_{2 \max }$ increased from $29.7 \% \pm 7.7 \%$ to $37.6 \% \pm 10.3 \%(\mathrm{p}<0.001)$ and from $17.6 \pm 4.7$ to $21.2 \pm 5.1 \mathrm{~mL} / \mathrm{kg} / \mathrm{min}(\mathrm{p}<0.001)$, respectively. Both groups completed their exercise program safely.

Conclusion In both groups, patients with ischemic cardiomyopathy who completed a 6-week supervised CR exercise program demonstrated remarkable improvements in cardiopulmonary function. This result implies that neither of the two groups showed higher efficacy in comparison to each other, but we can conclude that CR exercise in the rLVEF group was as effective and safe as that in the pLVEF group.
\end{abstract}

Keywords Exercise test, Exercise therapy, Myocardial ischemia, Stroke volume

Received August 31, 2015; Accepted October 20, 2015

Corresponding author: Young-Joon Lim

Department of Rehabilitation Medicine, Inje University Sanggye Paik Hospital, 1342 Dongil-ro, Nowon-gu, Seoul 01757, Korea. Tel: +82-2-950-1134, Fax: +82-2-935-3076, E-mail: yjlim817@hanmail.net

ORCID: Chul Kim (http://orcid.org/0000-0001-8223-2945); Hee Eun Choi (http://orcid.org/0000-0002-8753-929X); Young-Joon Lim (http://orcid. org/0000-0002-5834-9905).

() This is an open-access article distributed under the terms of the Creative Commons Attribution Non-Commercial License (http://creativecommons.org/ licenses/by-nc/4.0) which permits unrestricted noncommercial use, distribution, and reproduction in any medium, provided the original work is properly cited. Copyright $\odot 2016$ by Korean Academy of Rehabilitation Medicine 


\section{INTRODUCTION}

Cardiac rehabilitation (CR) is a cost effective intervention for treating coronary heart disease (CHD) that improves the functional capacity and reduces acute hospital admissions, and it can therefore make a valuable contribution to the healthcare management of an ageing population [1]. When the exercise-based CR was carried out, there was a significant decrease in fatal refraction including total mortality, cardiovascular mortality $[2,3]$, and improvement in cardiopulmonary fitness and psychological profiles [4].

It is already known that the large size of myocardial infarction (MI) causes ischemic heart failure (HF) and leads to left ventricular (LV) remodeling, and finally results in advanced LV dysfunction [5]. Therefore, major MI with a large infarction size was one of the major contraindications to exercise in the past. However, due to improvement in CR nowadays, it has been found that exercise based CR has a positive effect on exercise capacity as well as on LV remodeling in patients with severely impaired LV ejection fraction (LVEF) [6]. Therefore, ischemic cardiomyopathy is one of the diseases that improve after CR exercise.

Maximal oxygen consumption $\left(\mathrm{VO}_{2 \max }\right)$ is the best available objective measure of aerobic exercise capacity and it represents the maximum capacity of an individual's body to transport and use oxygen during incremental exercise [7]. Also in general, $\mathrm{VO}_{2 \max }$ is lower in patients with $\mathrm{CHD}$ than in age-matched healthy subjects [8], and many of these patients exhibit impaired LV function in response to exercise. However, some of the previous studies have reported a poor correlation between $\mathrm{VO}_{2 \max }$ and $\mathrm{LV}$ performance [9-11]. Furthermore, pharmacologic interventions that improve LV function in patients with HF may not necessarily result in increased maximal exercise capacity [7]. Therefore, we believe that improvement in both $\mathrm{VO}_{2 \max }$ and LVEF can be a more meaningful outcome regarding the effectiveness of CR exercise than improvement in only $\mathrm{VO}_{2 \max }$.

Several studies have concluded that exercise training in patients with $\mathrm{HF}$ and preserved $\mathrm{EF}$ (HFpEF) confers benefit in terms of enhancement in exercise capacity and health-related quality of life and it appears to be safe $[12,13]$. Also, several studies on HF with reduced ejection fraction have recently been reported and they show a positive effect of exercise training [14]. However, there are insufficient studies that compare the effect of CR between the ischemic cardiomyopathy with reduced LVEF (rLVEF) and preserved LVEF (pLVEF) groups.

The objective of this study was to compare the $\mathrm{VO}_{2 \max }$ and LVEF after completion of CR exercise in ischemic cardiomyopathy and to evaluate the differences between the rLVEF and pLVEF groups. Also, to evaluate the safety of CR, we observed the associated adverse effects or a critical event that required urgent medical care in both groups.

\section{MATERIALS AND METHODS}

\section{Subjects}

Patients with ischemic cardiomyopathy as a result of a recent acute myocardial infarction event ( $\leq 2$ months) and with LVEF $<50 \%$ were included as subjects. This study was performed retrospectively, and eligible subjects were selected from among the patients with ischemic HF who were referred for CR to our hospital between January 2009 and December 2013. The average time to CR enrollment since the coronary event was 39.2 days in the rLVEF group and 18.5 days in the pLVEF group. The exclusion criteria included the following: (1) non-ischemic cardiomyopathy, (2) inability to ambulate owing to physical problems (paresis induced by cerebral stroke, spinal cord injury, amputation, severe pain, dyspnea, etc.), (3) recurrent CHD, (4) underlying pulmonary disease (aspiration pneumonia, chronic obstructive pulmonary disease, pneumothorax, etc.), (5) impaired cognitive function (vascular dementia, Alzheimer's dementia, other psychological disease, etc.), and (6) inability to complete the 6 -week or the 18-session exercise training program (i.e., geographic or economic factors).

Since this study included acute ischemic heart failure patients, patients with LVEF $\geq 50 \%$ did not have common symptoms of heart failure that are found in chronic heart failure patients. This is the reason why we included patients with LVEF $<50 \%$ in this study. Patients with LVEF $\leq 40 \%$ with advanced symptoms were classified into the rLVEF group, and patients with $41 \%<\mathrm{LVEF}<50 \%$ with relatively mild symptoms were classified into the pLVEF group. It is important to note that the definition of preserved LVEF is different according the American Heart Association (AHA) HF guideline [15], in which LVEF 
$41 \%-49 \%$ is classified as borderline preserved ejection fraction and LVEF $\geq 50 \%$ is classified as preserved ejection fraction. Because we limited the inclusion criteria to LVEF $<50 \%$, we used the term 'preserved' for the group with $40 \%<\mathrm{LVEF}<50 \%$ rather than borderline preserved ejection fraction. The pLVEF group comprised 30 patients ( 24 men and 6 women; mean age, $57.6 \pm 14.1$ years); the rLVEF group comprised 18 patients ( 14 men and 4 women; mean age, 63.1 \pm 11.6 years) (Fig. 1). The study protocol was approved by the Institutional Review Board of Sanggye Paik Hospital (IRB No. 2014-12-001-001).

\section{Methods}

The CR exercise was performed under supervision at a single CR center using a standardized protocol. The patients were instructed to visit our CR clinic for preliminary examination, including the graded exercise test (GXT) during their first visit.

The GXT with ventilatory gas analysis was performed twice at baseline and at the 6 -week follow-up by using the modified Bruce protocol according to the AHA guideline. The purpose of this exercise test was to measure $\mathrm{VO}_{2 \max }$ and objectively monitor real-time electrocardiogram (ECG), heart rate (HR), blood pressure (BP), and Borg's 6-to-20 subjective rating of perceived exertion (RPE) during the test. For the GXT, a 12-channel real-time ECG tester for exercise load testing (Q4500; Quinton Instrument Co., Boston, MA, USA), a respiratory gas analyzer (TrueOne 2400; Parvo Medics Inc., Sandy, UT, USA), automatic blood pressure and pulse measuring instrument (Model 412; Quinton Instrument Co.), and treadmill for graded exercise testing (Medtrack ST55; Quinton Instrument Co.) were used.

Patients underwent hourly aerobic exercise training sessions, three times a week for 6 weeks. Each exercise session included a 10-minute warm-up, a 30-minute main exercise, and a 10-minute cool-down. Exercise intensity of a 30 -minute main exercise was $60 \%-85 \%$ of heart rate reserve (HRR). HRR was calculated according to the Karvonen formula, with each patient's maximum HR and resting HR obtained by the GXT. All training sessions were supervised by the medical staff and monitored with ECG, HR, and BP using telemetry monitoring system (Q-Tel RMS; Cardiac Science, Bothell, WA, USA), and Borg's RPE scale during and after each training session. The patient was monitored and asked about any adverse event or unexpected discomfort. Transthoracic echocardiography examination was also performed in all patients twice before and after completion of the 6-week exercise. By performing TTE examination, LVEF, stroke volume (SV), left ventricular end-systolic diameter (LVESD), and left ventricular end-diastolic diameter (LVEDD) were measured. The examination was performed under quiet resting conditions, and the findings were analyzed by a single cardiologist.

All patients who participated in the CR program were educated on risk factor management, smoking cessation, and were provided obesity and nutrition consultations.

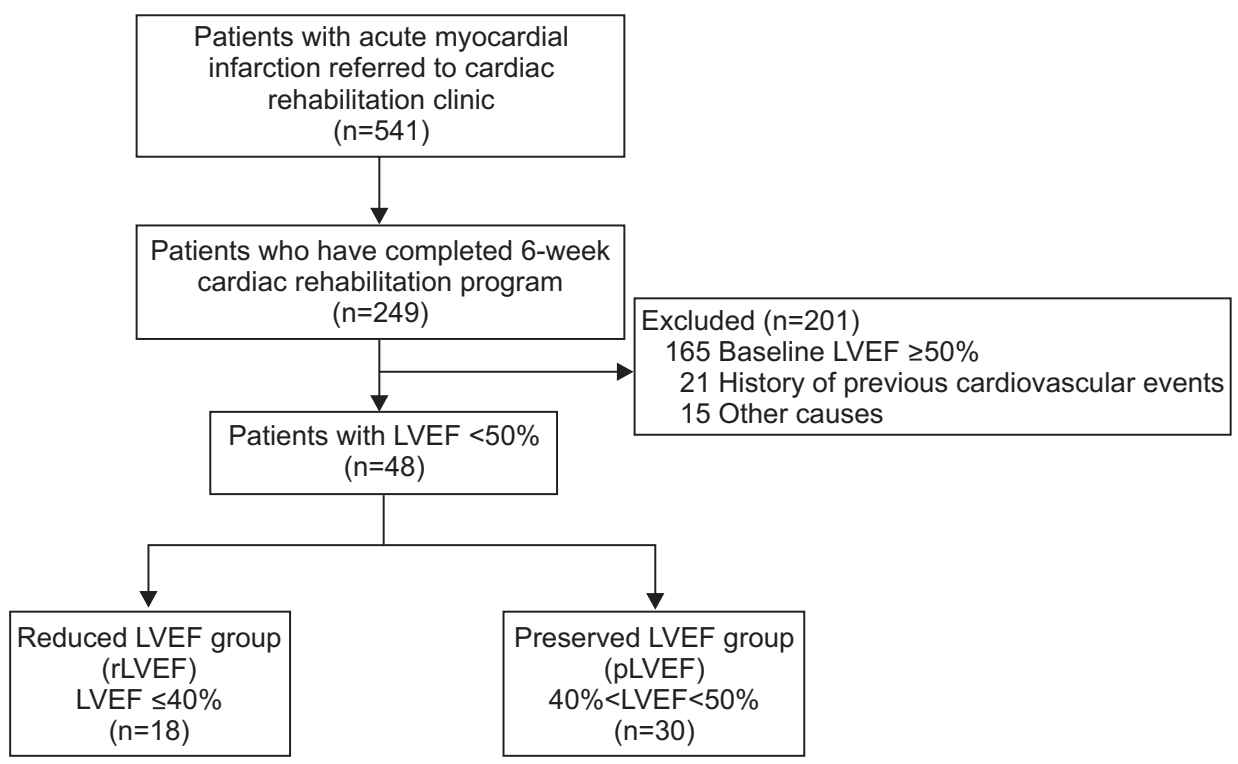

Fig. 1. Flow diagram of the study participants. LVEF, left ventricular ejection fraction. 
Table 1. Demographic data of subjects

\begin{tabular}{|c|c|c|c|}
\hline & pLVEF (n=30) & rLVEF $(n=18)$ & p-value \\
\hline Sex (male:female) & $24: 6$ & $14: 4$ & \\
\hline Age (yr) & $57.6 \pm 14.1$ & $63.1 \pm 11.6$ & 0.176 \\
\hline $\operatorname{BMI}\left(\mathrm{kg} / \mathrm{m}^{2}\right)$ & $24.3 \pm 2.3$ & $23.4 \pm 1.8$ & 0.164 \\
\hline \multicolumn{4}{|c|}{ No. of diseased vessels (\%) } \\
\hline 1 & $18(60.0)$ & $10(50.0)$ & 0.495 \\
\hline 2 & $9(30.0)$ & $2(10.0)$ & 0.098 \\
\hline 3 & $3(10.0)$ & $8(40.0)$ & 0.128 \\
\hline \multicolumn{4}{|c|}{ Stent inserted vessel (\%) } \\
\hline LAD & $21(70.0)$ & $12(66.6)$ & 0.647 \\
\hline RCA & $8(26.6)$ & $4(22.2)$ & 0.493 \\
\hline LCX & $3(10.0)$ & $2(11.1)$ & 0.813 \\
\hline CABG (\%) & $2(6.6)$ & $4(20.0)$ & 0.162 \\
\hline \multicolumn{4}{|c|}{ Post-intervention findings ${ }^{\mathrm{a})}(\%)$} \\
\hline 1 & $6(20.0)$ & $2(11.1)$ & 0.355 \\
\hline 2 & $1(3.3)$ & $1(5.5)$ & 0.774 \\
\hline 3 & $0(0)$ & $0(0)$ & - \\
\hline \multicolumn{4}{|l|}{ ECG } \\
\hline LBBB & $1(3.3)$ & $1(5.5)$ & 0.774 \\
\hline QRS widening & $2(6.6)$ & $3(16.6)$ & 0.346 \\
\hline Hypertension (\%) & $8(26.6)$ & $9(50)$ & 0.187 \\
\hline Diabetes (\%) & $4(13.3)$ & $7(38.8)$ & 0.072 \\
\hline \multicolumn{4}{|c|}{ History of smoking (\%) } \\
\hline Never & $19(63.3)$ & $12(66.6)$ & 0.641 \\
\hline Smoker & $9(30)$ & $4(22.2)$ & 0.234 \\
\hline Ex-smoker & $2(6.6)$ & $2(11.1)$ & 0.296 \\
\hline \multicolumn{4}{|c|}{ Current medications (\%) } \\
\hline ACEi & 37.5 & 43.8 & 0.333 \\
\hline ARB & 12.5 & 0 & 0.164 \\
\hline $\mathrm{ARB}+\mathrm{CCB}$ & 0.0 & 6.3 & 0.333 \\
\hline A B blocker & 25.0 & 25.0 & - \\
\hline B blocker & 62.5 & 43.8 & 0.083 \\
\hline CCB & 6.3 & 6.3 & - \\
\hline Statins & 100 & 100 & - \\
\hline Diuretics & 6.3 & 0 & 0.333 \\
\hline Nitrates & 43.8 & 56.3 & 0.164 \\
\hline Aspirin & 100 & 100 & - \\
\hline Clopidogrel & 93.8 & 100 & 0.333 \\
\hline
\end{tabular}

Values are presented as mean \pm standard deviation or number (\%).

pLVEF, preserved left ventricular ejection fraction; rLVEF, reduced left ventricular ejection fraction; BMI, body mass index; LAD, left anterior descending artery; RCA, right coronary artery; LCX, left circumflex artery; CABG, coronary artery bypass graft; LBBB, left bundle branch block; ECG, electrocardiogram; ACEi, angiotensin-converting-enzyme inhibitor; ARB, angiotensin II receptor blocker; CCB, calcium channel blocker; A B blocker, combined alpha- and beta-blockers; B blocker, beta-blocker.

${ }^{\text {a) }}$ Residual stenosis $\geq 50 \%$. 
Also, they received a drug prescription at the cardiology outpatient clinic.

\section{Statistical analysis}

The data was statistically analyzed with SPSS ver.18 (SPSS Inc., Chicago, IL, USA). In order to compare baseline characteristics of the two groups, student $t$-test was used. Paired t-test was used for comparing the parameters including LVEF, $\mathrm{VO}_{2 \max }, \mathrm{SV}$, LVEDD, and LVESD before and after the CR program. ANCOVA analysis was used for comparison of outcomes between the two groups since it was necessary to eliminate within group error variance and adjust imbalances in prognostic variables. Statistical significance was defined as $p$-value of less than 0.05 .

Table 2. Laboratory and echocardiographic data at baseline

\begin{tabular}{|c|c|c|c|}
\hline & $\begin{array}{l}\text { pLVEF } \\
(n=30)\end{array}$ & $\begin{array}{l}\text { rLVEF } \\
(n=18)\end{array}$ & p-value \\
\hline \multicolumn{4}{|l|}{ Laboratory data } \\
\hline $\mathrm{VO}_{2 \max }(\mathrm{mL} / \mathrm{kg} / \mathrm{min})$ & $24.1 \pm 6.3$ & $17.6 \pm 4.7$ & 0.001 \\
\hline $\mathrm{HR}_{\text {rest }}$ (beats/min) & $69.6 \pm 9.8$ & $78.1 \pm 12.3$ & 0.223 \\
\hline $\mathrm{SBP}_{\text {rest }}(\mathrm{mmHg})$ & $113.6 \pm 15.4$ & $113.0 \pm 15.6$ & 0.773 \\
\hline $\mathrm{DBP}_{\text {rest }}(\mathrm{mmHg})$ & $75.0 \pm 8.5$ & $79.5 \pm 11.7$ & 0.859 \\
\hline Cholesterol (mg/dL) & $166.4 \pm 36.7$ & $165.3 \pm 35.1$ & 0.682 \\
\hline LDL (mg/dL) & $109.3 \pm 29.3$ & $117.2 \pm 37.5$ & 0.423 \\
\hline HDL (mg/dL) & $42.2 \pm 6.8$ & $40.6 \pm 9.3$ & 0.494 \\
\hline $\mathrm{TG}(\mathrm{mg} / \mathrm{dL})$ & $110.0 \pm 64.4$ & $116.1 \pm 57.1$ & 0.745 \\
\hline hs-CRP (mg/dL) & $0.7 \pm 1.2$ & $1.2 \pm 1.6$ & 0.283 \\
\hline HbAlc (\%) & $6.3 \pm 1.5$ & $7.3 \pm 2.4$ & 0.164 \\
\hline \multicolumn{4}{|l|}{ Echocardiographic data } \\
\hline $\operatorname{LVEF}(\%)$ & $45.1 \pm 4.8$ & $29.7 \pm 7.7$ & 0.001 \\
\hline $\mathrm{SV}(\mathrm{mL})$ & $63.4 \pm 17.6$ & $59.5 \pm 12.9$ & 0.416 \\
\hline $\operatorname{LVESD}(\mathrm{cm})$ & $4.8 \pm 1.1$ & $3.9 \pm 0.4$ & 0.002 \\
\hline LVEDD (cm) & $5.9 \pm 0.9$ & $5.1 \pm 0.4$ & 0.002 \\
\hline
\end{tabular}

Values are presented as mean \pm standard deviation. pLVEF, preserved left ventricular ejection fraction; rLVEF, reduced left ventricular ejection fraction; $\mathrm{VO}_{2 \max }$ maximal oxygen consumption; $\mathrm{HR}_{\text {rest }}$, resting heart rate; $\mathrm{SBP}_{\text {rest }}$, resting systolic blood pressure; $\mathrm{DBP}_{\text {rest }}$, resting diastolic blood pressure; LDL, low density lipoprotein; HDL, high density lipoprotein; TG, triglyceride; hs-CRP, high sensitivity C-reactive protein; HbAlc, glycated hemoglobin; LVEF, left ventricular ejection fraction; SV, stroke volume; LVESD, left ventricular end-systolic diameter; LVEDD, left ventricular end-diastolic diameter.

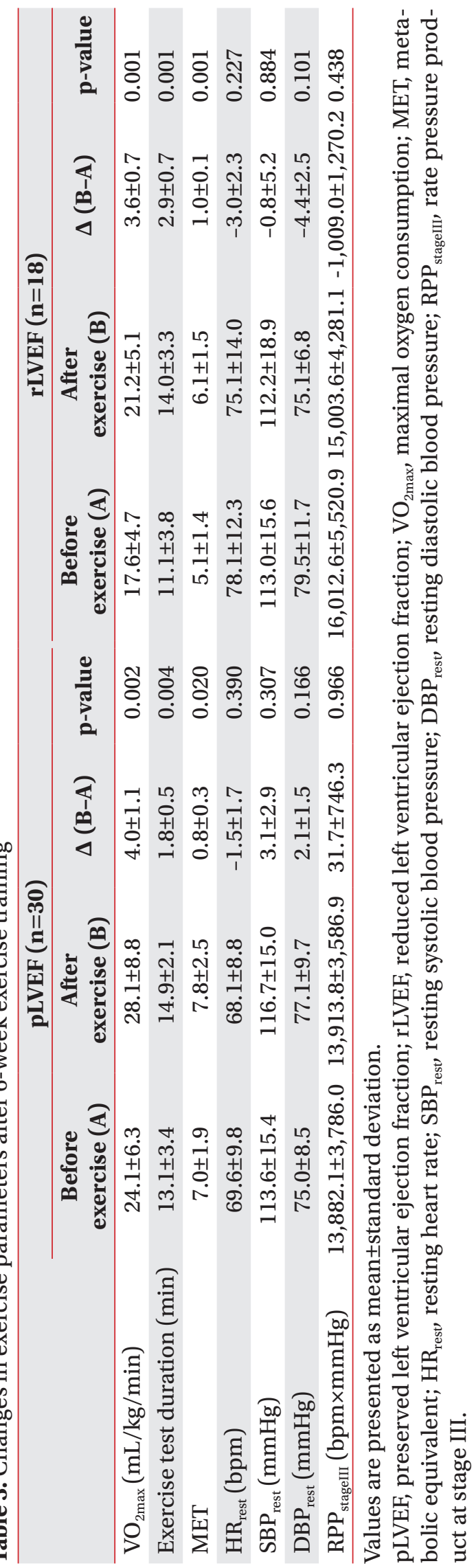

www.e-arm.org 


\section{RESULTS}

Comparison of demographic data between the two groups did not reveal significant differences (Table 1). Baseline laboratory data also showed no significant differences between the two groups except for $\mathrm{VO}_{2 \max }$. Among the parameters obtained from echocardiography, LVEF, LVEDD, and LVESD showed significant differences between the two groups, except for SV (Table 2). In the pLVEF group, LVEF increased from $45.1 \% \pm 4.8 \%$ to $52.5 \% \pm 9.6 \%$ (change rate, $16.2 \% \pm 3.1 \%$ ) and $\mathrm{VO}_{2 \max }$ increased from $24.1 \pm 6.3$ to $28.1 \pm 8.8 \mathrm{~mL} / \mathrm{kg} / \mathrm{min}$ (change rate, $17.8 \% \pm 5.0 \%$ ). In the rLVEF group, LVEF and $\mathrm{VO}_{2 \max }$ increased from $29.7 \% \pm 7.7 \%$ to $37.6 \% \pm 10.3 \%$ (change rate, $30.2 \% \pm 7.5 \%$ ) and from $17.6 \pm 4.7$ to $21.2 \pm 5.1 \mathrm{~mL} / \mathrm{kg} / \mathrm{min}$ (change rate, $23.2 \% \pm 4.8 \%$ ), respectively. All results were statistically significant in both groups (Tables 3, 4 and Figs. 2, 3).

In both groups, the absolute change value of LVEF

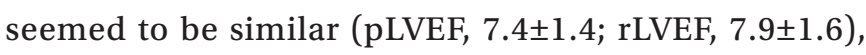
but since the two groups had different baseline LVEF, we also evaluated the relative change rate instead of the absolute change. Our aim was to observe the improvement rate rather than just comparing the change in values and this evaluation could also be applied for $\mathrm{VO}_{2 \max }$ analysis. Relative changes in LVEF and $\mathrm{VO}_{2 \max }$, both parameters showed larger differences than those in absolute changes. In order to compare the significant differences between the two groups, we used ANCOVA analysis. The between-subjects effect analysis showed that both LVEF and $\mathrm{VO}_{2 \max }$ showed significant improvement after CR exercise, but we could not conclude that the rLVEF group showed greater statistically significant improvement than the pLVEF group (between-subject effects in LVEF, $\left.\mathrm{p}=0.61, \mathrm{VO}_{2 \max }, \mathrm{p}=0.68\right)$. Also, throughout the total 720 hours of exercise (pLVEF, 450 exercise-hours; rLVEF, 270 exercise-hours), there were no adverse effects or a critical event that required urgent medical care or cessation of exercise in both groups.

\section{DISCUSSION}

The participation rate for the CR program has increased recently; however, the rate is still low despite evidence that participation in a CR program confers clinically significant benefits for patients diagnosed with cardiovascular disease [16]. One of the main reasons for low attendance is that especially the patients with low LVEF and poor cardiopulmonary function do not actively participate because of misconceptions such as CR is not safe and is relatively contraindicated; therefore, not beneficial [17]. However, findings of recent studies support the claim that patients with poor cardiopulmonary function and reduced LVEF are no longer a contraindication to CR nowadays and attending a CR program more actively has a positive effect on long-term mortality $[18,19]$. The study by Beauchamp et al. [18] provided evidence for the longterm benefits of CR and suggested that a dose-response relationship may exist between the number of sessions attended and long-term mortality. The study comprised a total of 281 men and women eligible for CR following MI, coronary artery bypass surgery or percutaneous interventions. The mortality risk for non-attenders was $58 \%$ greater than for attenders. Participants who attended $<25 \%$ of sessions had a mortality risk more than twice that of participants attending $\geq 75 \%$ of sessions. There-

Table 4. Changes in echocardiographic parameters after 6-week exercise training

\begin{tabular}{|c|c|c|c|c|c|c|c|c|}
\hline & \multicolumn{4}{|c|}{ pLVEF $(n=30)$} & \multicolumn{4}{|c|}{ rLVEF $(n=18)$} \\
\hline & $\begin{array}{c}\text { Before } \\
\text { exercise (A) }\end{array}$ & $\begin{array}{c}\text { After } \\
\text { exercise (B) }\end{array}$ & $\begin{array}{c}\Delta \\
(B-A)\end{array}$ & p-value & $\begin{array}{c}\text { Before } \\
\text { exercise (A) }\end{array}$ & $\begin{array}{c}\text { After } \\
\text { exercise (B) }\end{array}$ & $\underset{(B-A)}{\Delta}$ & p-value \\
\hline LVEF (\%) & $45.1 \pm 4.8$ & $52.5 \pm 9.6$ & $7.4 \pm 1.4$ & 0.001 & $29.7 \pm 7.7$ & $37.6 \pm 10.3$ & $7.9 \pm 1.6$ & 0.001 \\
\hline $\mathrm{SV}(\mathrm{mL})$ & $63.4 \pm 17.6$ & $68.3 \pm 17.0$ & $4.8 \pm 13.9$ & 0.067 & $59.5 \pm 12.9$ & $69.6 \pm 11.6$ & $9.5 \pm 2.9$ & 0.002 \\
\hline LVESD (cm) & $4.8 \pm 1.1$ & $4.6 \pm 1.1$ & $-0.2 \pm 0.7$ & 0.027 & $3.9 \pm 0.4$ & $3.6 \pm 0.4$ & $-0.3 \pm 0.1$ & 0.006 \\
\hline LVEDD (cm) & $5.9 \pm 0.9$ & $5.8 \pm 0.9$ & $-0.1 \pm 0.1$ & 0.387 & $5.1 \pm 0.4$ & $5.1 \pm 0.2$ & $-0.1 \pm 0.1$ & 0.976 \\
\hline
\end{tabular}

Values are presented as mean \pm standard deviation.

pLVEF, preserved left ventricular ejection fraction; rLVEF, reduced left ventricular ejection fraction; LVEF, left ventricular ejection fraction; SV, stroke volume; LVESD, left ventricular end-systolic diameter; LVEDD, left ventricular enddiastolic diameter. 


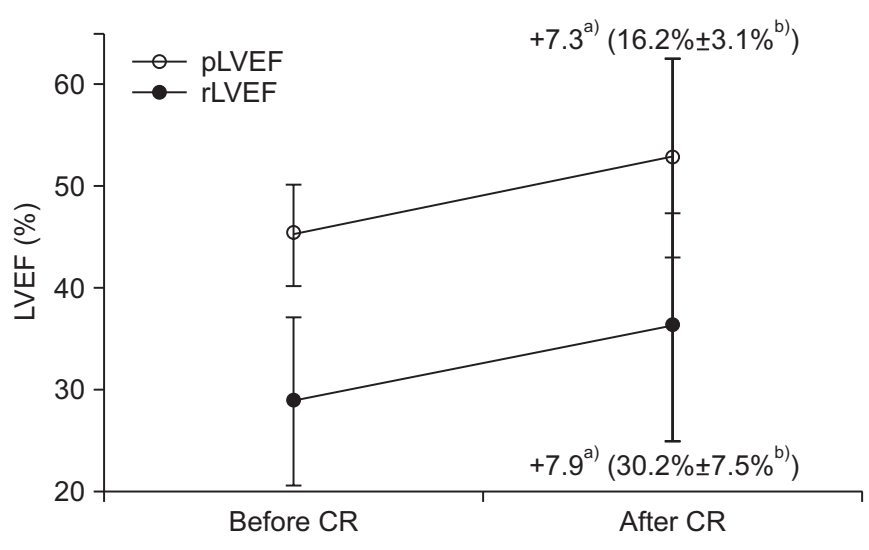

Fig. 2. Changes in LVEF after cardiac rehabilitation (CR) exercise. pLVEF, preserved left ventricular ejection fraction; rLVEF, reduced left ventricular ejection fraction. ${ }^{a)} \mathrm{Ab}$ solute change value, ${ }^{\text {b) }}$ rate of change \pm standard deviation.

fore, attending a CR program more actively can lead to an anticipated reduction in further coronary events, and hence, it is necessary to encourage ischemic cardiomyopathy patients to participate in CR programs. Since many studies have proven that CR forms an important part of secondary coronary artery disease prevention [18-21], our study provides meaningful results which suggest that CR is safe even in patients with reduced LVEF as well as it is effective in improving their cardiopulmonary function. Our findings can positively influence the awareness and motivation of CHD patients for participation in CR.

Progressive LV enlargement, dilatation, and global or regional $\mathrm{LV}$ dysfunction can occur as a result of ischemic HF. These changes can act as important prognostic factors in the clinical course of chronic HF, particularly after a MI. These changes also known as 'remodeling' can precede deterioration in exercise capacity, and LV dilatation is associated with a significant reduction in cardiac performance [22-24]. In several previous studies, the benefits of $\mathrm{CR}$ exercise training during the recovery period after ischemic heart disease have been well established [25]. Recently, these benefits have been extended to include patients with reduced LV function [26-28]. Two previous studies reported abnormal remodeling in some patients; although training did not appear to have any effect on this process $[29,30]$. Also, two recent studies related to the effects of exercise training on $\mathrm{LV}$ remodeling showed that exercise training has beneficial effects on LV remodeling and it even reverses $L V$ remodeling in patients with heart failure $[31,32]$. Also, it has been observed that CR has a

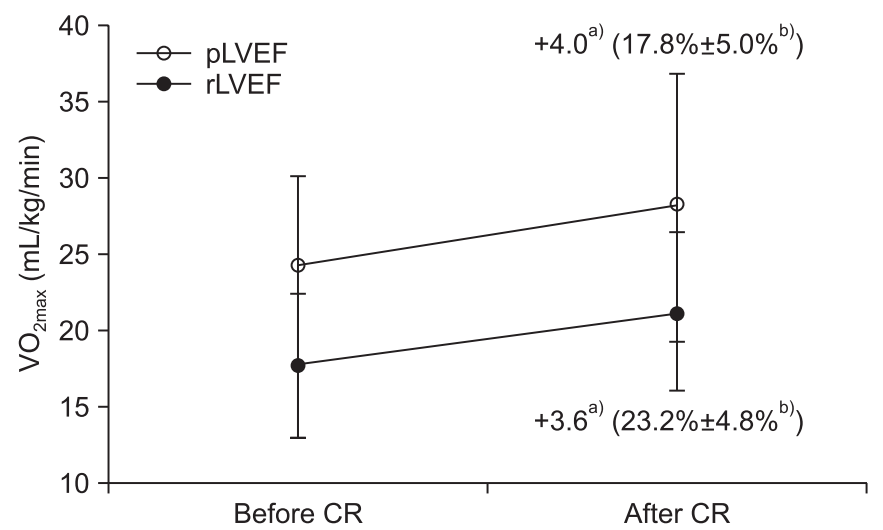

Fig. 3. Changes in $\mathrm{VO}_{2 \max }$ after cardiac rehabilitation (CR) exercise. pLVEF, preserved left ventricular ejection fraction; rLVEF, reduced left ventricular ejection fraction. ${ }^{\text {a) }}$ Absolute change value, ${ }^{\text {b) }}$ rate of change \pm standard deviation.

direct influence on the myocardium, and it increases the myocardial perfusion which in turn increases the exercise capacity. This was confirmed by cardiac magnetic resonance imaging and quantitative positron emission tomography myocardial flow reserve (PET-MFR) assessments [33-36]. These previous studies have shown that CR has a significant benefit in recovery of LV function after LV remodeling.

Positive effects on LV function also support the importance of CR exercise, and therefore, the significance of active participation in CR by patients with reduced LVEF is emphasized and our significant results can support this concept. The effectiveness of CR has been extensively studied and the positive effect of CR is widely known these days. Dubach et al. [6] reported that a highintensity, 2-month residential CR program resulted in substantial increases in exercise capacity among patients with reduced LV function. The study included 25 patients with reduced LV function and the patients resided in a rehabilitation center for 2 months and underwent a training program consisting of two 1-hour sessions of walking daily, along with four monitored 45-minute sessions of stationary cycling weekly. $\mathrm{VO}_{2 \max }$ increased by $26 \%$ in the exercise group, whereas the control values did not change. On comparing with our study, our study included 48 patients and more specifically patients with very low LVEF $(<30 \%)$ which could lead to a mean EF of $28.9 \% \pm 8.1 \%$ in the rLVEF group while the mean EF in the study by Dubach et al. [6] was $31.5 \% \pm 6.7 \%$. Patients 
with ischemic cardiomyopathy who completed a 6-week supervised CR exercise program demonstrated safe sustained improvements in LVEF and $\mathrm{VO}_{2 \max }$, regardless of the initial baseline EF values. These findings can be supported by studies performed by Nishi et al. [37] and Vanhees et al. [38], which showed that CR in patients with reduced $\mathrm{EF}(<40 \%)$ had as much efficacy as that in cardiovascular disease patients with normal range $\mathrm{EF}$ as well as they proposed the safety of CR in both groups. The results of our study show that CR is effective in both groups, implying that neither the pLVEF group nor the rLVEF group showed higher efficacy in comparison to each other. Also, it should be emphasized that in our study, early CR was performed within an average 23.2 days after acute MI, even in patients with very low $\mathrm{EF}(<30 \%, n=7)$, and it was performed without any adverse events.

There are some limitations in this study. We aimed to recruit an equal number of patients in both groups; however, we were unable to include more patients in the rLVEF group within the selected period. A further study including a larger rLVEF group would be more representative and would convey a more significant result. Also, our study evaluated the difference over a 6 -week period only; therefore, follow-up evaluation over a longer period should be considered in future studies.

We were able to obtain satisfactory results since the study was performed safely without any unexpected or lethal event in patients with very low LVEF, and this proved that early CR can be performed safely in patients with rLVEF and it has a positive effect on recovery of cardiopulmonary function.

In conclusion, the present study demonstrated two important findings. First, the effects of CR in patients with rLVEF were as significant as those in patients with pLVEF. Second, CR can be performed safely in the rLVEF group and it has a positive effect on recovery of cardiopulmonary function. Given the significant clinical benefits of CR, greater attention should be focused on increasing referrals, reducing barriers to attendance, and achieving reductions in CHD morbidity and mortality after CR completion. We believe that our findings can strongly support the use of $\mathrm{CR}$, and hopefully, wide implementation of such programs may favorably impact patient participation.

\section{CONFLICT OF INTEREST}

No potential conflict of interest relevant to this article was reported.

\section{REFERENCES}

1. Hedback B, Perk J, Hornblad M, Ohlsson U. Cardiac rehabilitation after coronary artery bypass surgery: 10 -year results on mortality, morbidity and readmissions to hospital. J Cardiovasc Risk 2001;8:153-8.

2. Taylor RS, Brown A, Ebrahim S, Jolliffe J, Noorani H, Rees K, et al. Exercise-based rehabilitation for patients with coronary heart disease: systematic review and meta-analysis of randomized controlled trials. Am J Med 2004;116:682-92.

3. O'Connor GT, Buring JE, Yusuf S, Goldhaber SZ, Olmstead EM, Paffenbarger RS, et al. An overview of randomized trials of rehabilitation with exercise after myocardial infarction. Circulation 1989;80:234-44.

4. Dugmore LD, Tipson RJ, Phillips MH, et al. Changes in cardiorespiratory fitness, psychological wellbeing, quality of life, and vocational status following a 12 month cardiac exercise rehabilitation programme. Heart 1999;81:359-66.

5. Sutton MG, Sharpe N. Left ventricular remodeling after myocardial infarction: pathophysiology and therapy. Circulation 2000;101:2981-8.

6. Dubach P, Myers J, Dziekan G, Flint EJ, Stentiford $\mathrm{NH}$, Bone MF, et al. Effect of exercise training on myocardial remodeling in patients with reduced left ventricular function after myocardial infarction: application of magnetic resonance imaging. Circulation 1997;95:2060-7.

7. Ehsani AA, Biello D, Seals DR, Austin MB, Schultz J. The effect of left ventricular systolic function on maximal aerobic exercise capacity in asymptomatic patients with coronary artery disease. Circulation 1984;70:552-60.

8. Weber KT, Kinasewitz GT, Janicki JS, Fishman AP. Oxygen utilization and ventilation during exercise in patients with chronic cardiac failure. Circulation 1982;65:1213-23.

9. Kramer N, Susmano A, Shekelle RB. The "false negative" treadmill exercise test and left ventricular dysfunction. Circulation 1978;57:763-8. 
10. Benge W, Litchfield RL, Marcus ML. Exercise capacity in patients with severe left ventricular dysfunction. Circulation 1980;61:955-9.

11. Port S, McEwan P, Cobb FR, Jones RH. Influence of resting left ventricular function on the left ventricular response to exercise in patients with coronary artery disease. Circulation 1981;63:856-63.

12. Taylor RS, Davies EJ, Dalal HM, Davis R, Doherty P, Cooper $\mathrm{C}$, et al. Effects of exercise training for heart failure with preserved ejection fraction: a systematic review and meta-analysis of comparative studies. Int J Cardiol 2012;162:6-13.

13. Pandey A, Parashar A, Kumbhani DJ, Agarwal S, Garg J, Kitzman D, et al. Exercise training in patients with heart failure and preserved ejection fraction: metaanalysis of randomized control trials. Circ Heart Fail 2015;8:33-40.

14. Reibis R, Jannowitz C, Halle M, Pittrow D, Gitt A, Voller $\mathrm{H}$. Management and outcomes of patients with reduced ejection fraction after acute myocardial infarction in cardiac rehabilitation centers. Curr Med Res Opin 2015;31:211-9.

15. Yancy CW, Jessup M, Bozkurt B, Butler J, Casey DE Jr, Drazner MH, et al. 2013 ACCF/AHA guideline for the management of heart failure: a report of the American College of Cardiology Foundation/American Heart Association Task Force on Practice Guidelines. J Am Coll Cardiol 2013;62:e147-239.

16. Wyer SJ, Earll L, Joseph S, Harrison J, Giles M, Johnston $\mathrm{M}$. Increasing attendance at a cardiac rehabilitation programme: an intervention study using the Theory of Planned Behaviour. Coron Health Care 2001;5:154-9.

17. Bethell HJ. Exercise in cardiac rehabilitation. Br J Sports Med 1999;33:79-86.

18. Beauchamp A, Worcester M, Ng A, Murphy B, Tatoulis $\mathrm{J}$, Grigg L, et al. Attendance at cardiac rehabilitation is associated with lower all-cause mortality after 14 years of follow-up. Heart 2013;99:620-5.

19. Ali M, Qadir F, Javed S, Khan ZN, Asad S, Hanif B. Factors affecting outpatient cardiac rehabilitation attendance after acute myocardial infarction and coronary revascularization: a local experience. J Pak Med Assoc 2012;62:347-51.

20. Arthur HM, Suskin N, Bayley M, Fortin M, Howlett J, Heckman G, et al. The Canadian Heart Health Strat- egy and Action Plan: cardiac rehabilitation as an exemplar of chronic disease management. Can J Cardiol 2010;26:37-41.

21. Lloyd-Jones DM, Hong Y, Labarthe D, Mozaffarian D, Appel LJ, Van Horn L, et al. Defining and setting national goals for cardiovascular health promotion and disease reduction: the American Heart Association's strategic Impact Goal through 2020 and beyond. Circulation 2010;121:586-613.

22. Gaudron P, Eilles C, Kugler I, Ertl G. Progressive left ventricular dysfunction and remodeling after myocardial infarction: potential mechanisms and early predictors. Circulation 1993;87:755-63.

23. Goldstein S, Sharov VG, Cook JM, Sabbah HN. Ventricular remodeling: insights from pharmacologic interventions with angiotensin-converting enzyme inhibitors. Mol Cell Biochem 1995;147:51-5.

24. Pfeffer MA, Braunwald E. Ventricular remodeling after myocardial infarction: experimental observations and clinical implications. Circulation 1990;81:1161-72.

25. American Association of Cardiovascular and Pulmonary Rehabilitation. Guidelines for cardiac rehabilitation program. 2nd ed. Champaign: Human Kinetics; 1995.

26. Adamopoulos S, Coats AJ, Brunotte F, Arnolda L, Meyer $\mathrm{T}$, Thompson $\mathrm{CH}$, et al. Physical training improves skeletal muscle metabolism in patients with chronic heart failure. J Am Coll Cardiol 1993;21:1101-6.

27. Sullivan MJ, Higginbotham MB, Cobb FR. Exercise training in patients with severe left ventricular dysfunction: hemodynamic and metabolic effects. Circulation 1988;78:506-15.

28. Hambrecht R, Niebauer J, Fiehn E, Kalberer B, Offner B, Hauer K, et al. Physical training in patients with stable chronic heart failure: effects on cardiorespiratory fitness and ultrastructural abnormalities of leg muscles. J Am Coll Cardiol 1995;25:1239-49.

29. Giannuzzi P, Tavazzi L, Temporelli PL, Corra U, Imparato A, Gattone M, et al. Long-term physical training and left ventricular remodeling after anterior myocardial infarction: results of the Exercise in Anterior Myocardial Infarction (EAMI) trial. EAMI Study Group. J Am Coll Cardiol 1993;22:1821-9.

30. Jette M, Heller R, Landry F, Blumchen G. Randomized 4-week exercise program in patients with impaired left ventricular function. Circulation 1991;84:1561-7. 
31. Haykowsky M, Scott J, Esch B, Schopflocher D, Myers J, Paterson I, et al. A meta-analysis of the effects of exercise training on left ventricular remodeling following myocardial infarction: start early and go longer for greatest exercise benefits on remodeling. Trials 2011;12:92.

32. Chen YM, Li ZB, Zhu M, Cao YM. Effects of exercise training on left ventricular remodelling in heart failure patients: an updated meta-analysis of randomised controlled trials. Int J Clin Pract 2012;66:782-91.

33. Lee BC, Chen SY, Hsu HC, Su MY, Wu YW, Chien KL, et al. Effect of cardiac rehabilitation on myocardial perfusion reserve in postinfarction patients. Am J Cardiol 2008;101:1395-402.

34. Linxue L, Nohara R, Makita S, Hosokawa R, Hata T, Okuda $\mathrm{K}$, et al. Effect of long-term exercise training on regional myocardial perfusion changes in patients with coronary artery disease. Jpn Circ J 1999;63:73-8.

35. Makaryus J, Tobe L, Alharbi M, Kim D, Ershova S, Robi
A, et al. Cardiac rehabilitation improves myocardial blood flow reserve as assessed by positron emission tomographic myocardial perfusion imaging. J Am Coll Cardiol 2014;63(12 Suppl):A1017.

36. Lee BC, Hsu HC, Tseng WY, Su MY, Chen SY, Wu YW, et al. Effect of cardiac rehabilitation on angiogenic cytokines in postinfarction patients. Heart 2009;95:10128.

37. Nishi I, Noguchi T, Iwanaga Y, Furuichi S, Aihara N, Takaki H, et al. Effects of exercise training in patients with chronic heart failure and advanced left ventricular systolic dysfunction receiving $\beta$-blockers. Circ J 2011;75:1649-55.

38. Vanhees L, Stevens A, Schepers D, Defoor J, Rademakers F, Fagard R. Determinants of the effects of physical training and of the complications requiring resuscitation during exercise in patients with cardiovascular disease. Eur J Cardiovasc Prev Rehabil 2004;11:304-12. 